\title{
Inappropriate emergency admissions from nursing homes in Switzerland: a retrospective chart review
}

Katharina Gaertner ( $\nabla$ katharina.gaertner@uni-wh.de )

Universitat Witten/Herdecke https://orcid.org/0000-0001-7711-2842

Sabine K. Schuh

Inselspital Universitatsspital Bern

\section{Barbara Löw}

Solothurner Spitaler AG

Michael Simon

Universitatsspital Basel

Franziska Zúñiga

Universitatsspital Basel

Martin Müller

Inselspital Universitatsspital Bern

Original research

Keywords: Emergency Department, Nursing Homes, Health-care management, Cost-effectiveness, Inappropriate Visits

Posted Date: July 20th, 2020

DOI: https://doi.org/10.21203/rs.3.rs-41758/v1

License: (9) This work is licensed under a Creative Commons Attribution 4.0 International License.

Read Full License 


\section{Abstract \\ Background}

increasing numbers of multimorbid patients living in long-term care (LTC) residential facilities are challenging ambulant care. In times of overcrowded emergency departments (ED), inappropriate ED visits need to be avoided to ensure optimal health care. This study aimed to determine and characterize inappropriate ED consultations of LTC residents including ED resource consumption.

\section{Methods}

this retrospective chart review was conducted at the ED of a Swiss tertiary hospital with a catchment area of about two million people. The analysis included 1'276 LTC-residents referred to the study centre between January 2015 and December 2017. Patient and consultation characteristics (age, gender, Charlson Comorbidity Index, as well as type and time of admission, length of stay in the ED, presence or absence of a consecutive hospitalization, and data on ED resource consumption) were extracted from the ED's documentation system. Appropriateness was assessed using an established evaluation protocol. All variables were described in absolute numbers, percentages or median and interquartile range (IQR). Associations with inappropriateness status were tested with chi-square or Wilcoxon rank sum test respectively. A multivariable logistic regression analysis was preformed to identify predictors of inappropriate ED visits.

\section{Results}

The referred LTC-residents had a median age of 84 (IQR 78-89) years; 77 referrals (6.0\%) were assessed as inappropriate. The final model revealed increased odds for an inappropriate admission for a less acute triage class and patients with connective tissue disease (both $p \leq 0.001$ ), but lower odds for night-time admissions $(p=0.035)$ and the presence of cerebrovascular diseases $(p=0.043)$, respectively. The ED resource consumption differed significantly between appropriate and inappropriate visits $(p \leq 0.001)$.

\section{Conclusion}

Inappropriate admissions from nursing homes were low and less resource intensive than appropriate admissions. Preventive strategies focusing on high-quality ambulatory day-care might further reduce inappropriate emergency admissions.

\section{Background}

Due to increasing age, multimorbidity, and polypharmacy with consecutive adverse drug reactions, patients living in long-term care (LTC) residential facilities are prone to acute and chronic illnesses $(1,2)$. 
Compared to their community-dwelling peers they have an elevated level of multimorbidity resulting in high admission rates to hospitals and emergency departments $(E D)(3,4)$. The reasons for admission of LTC patients to an ED cover a wide array of conditions. Often cited are fall-related injuries and infections $(5-7)$ as well as respiratory and circulatory diseases (8). As admission rates are rising $(6,9)$ and, in turn, are a risk factor for increased morbidity and costs (10), several strategies to achieve a reduction in allcause transfers exist (11). Special focus has been given to avoidable and inappropriate admissions, where the latter are defined as admissions due to a condition that could have been treated somewhere else than in the ED, e.g. by a general practitioner or a specialist in an ambulatory care setting (12). Depending on the measuring tool used, $4-55 \%$ of ED visits have been considered inappropriate $(10,12-$ 14). Variations in hospital admission rates from nursing homes are not only observed between countries, but also within countries (15). Reasons for high admission rates have been suggested to be lack of advance care planning (ACP), lack of access to primary care services in the LTC facility, insufficiently trained staff as well as understaffing and poor interprofessional collaboration $(14,16)$. This study aims to assess patterns, and rates of inappropriate ED visits of patients referred from LTC facilities to a Swiss tertiary care hospital, describing the incidence, risk factors, and ED resource utilization of inappropriate visits.

\section{Methods}

\section{Study design, setting and sample}

This is a retrospective cohort study at the ED of University hospital of Bern (Inselspital) with a catchment area of about two million people, and 45'000 ED consultations per year (17). The three-year study period started on January 1, 2015 and ended on December 31, 2017. All consultation records from LTC residents with at least 65 years of age at admission registered as "referral from nursing home" in the ED's electronic health care record E-Care (E-Care, ED 2.1.3.0, Turnhout, Belgium) were included.

\section{Variables and measurements}

The main variable of interest, inappropriate ED visits, was assessed with the Appropriateness Evaluation Protocol (18) adapted by Finn et al. (13). The assessment consists of a dichotomized 10-item list, where the absence or presence of the following characteristics of patient consultations is determined: $i$ ) hospitalization needed, ii) a history of trauma with suspected fracture, iii) radiology examination needed, iv) plaster application needed, v) suspicion of a cerebral event, vi) difficult indwelling urethral catheter insertion, vii) percutaneous endoscopic gastrostomy tube insertion, viii) requirement of intravenous antibiotics, iv) suitable observations unable to be provided, and $\mathrm{x}$ ) procedure unable to be performed in a nursing home. The items were assessed sequentially and as soon as one item was present in the case record, the visit was rated as "appropriate". If all items were absent, the visit was rated as "inappropriate" (see Additional file 1: decision-tree inappropriate ED-visits).

The characterizing variables age and gender, admission-type (e.g. ambulance-transfers, walk-in patients, patients with reference from a general practitioner), day and time of admission, and triage status 
according to the Swiss triage scale (19) were extracted directly from E-care documentation for all included patient records. Further, specific comorbidities integrated in the Charlson Comorbidity Index (CCI) (20), i.e. congestive heart failure, past myocardial infarction, chronic kidney disease, diabetes, liver disease, chronic obstructive lung disease, dementia, cerebrovascular disease, hemi-/paraplegia, peripheral artery occlusive disease, connective tissue disease, peptic ulcer disease, and malignancy, were identified from the patients files. The $\mathrm{CCl}$ allows appraising the risk of death over ten years due to comorbid conditions. For this study, the rating-scale based on the paper by Halfon et al. (21) was used.

Additionally, the following outcome parameter were extracted from the administrative database (OpenText Suite for SAP® Solutions, OpenText Corp., Waterloo, Canada): Length of stay (LOS) in the ED (hours), LOS in the hospital (days), Intensive care unit (ICU) admission, and In-hospital death. Lastly, ED resources (physician and nurse work as well as used laboratory examination or imagery) were assessed and total ED-costs calculated. All staff members document their performed procedures individually for every consultation using procedural codes from the TARMED Suisse catalogue (TARMED Suisse, TARMED, 01.06.2012) required by the health care law. Those codes are measured in tax points ([TP], medical currency). 1 TP is about 1 US- $\$$ and depends among others on the hospital and region and is here used as a medical currency to compare the resource consumption between appropriate and inappropriate ED visits.

\section{Data handling}

Health related data of all ED patients were pseudonymized and transferred from E-Care into a database, which was used for this study. The database was screened for "referral from nursing home" and the retrieved health related data was independently assessed for appropriateness of the referral by two of the authors (BL and SS). In case of dissent, appropriateness of referral was set after discussion with a third author (MM). The interrater agreement was assessed using Gwet's AC, the statistic of choice for the case of two assessors and low prevalence data (22). Gwet's AC > 0.8 was considered a "very good" agreement (23).

Comorbidities and the comorbidity-scores of the sample were coded manually by one of the authors (BL) using the diagnosis field of E-care documentation.

\section{Statistical analysis}

The statistical analysis was performed with Stata ${ }^{\circledR} 13.1$ (StataCorp, The College Station, Texas, USA). Characteristics of all consultations grouped by appropriateness are presented as absolute numbers and percentages, respectively as median and interquartile range (IQR) as appropriate. Differences between the two groups (appropriate vs. inappropriate) were tested with a chi-square respectively Wilcoxon rank sum test as appropriate.

A stepwise backward logistic regression analysis (stepwise removal of variables with $p>0.2$ ) was conducted to identify predictors of inappropriate ED visits. Goodness of fit was tested using the Hosmer and Lemeshow test and the discrimination using ROC-curve analysis with Harrell's c-statistic. The 
strength of the association was presented as an odds ratio accompanied by its $95 \%$ confidence interval (Cl). A p-value of $<0.05$ was considered significant.

\section{Ethical considerations}

The study was performed according to Swiss law. The Bern ethics committee registered the study as a quality evaluation study (KEK 2019 - 00512) and waived the need for informed consent. General informed consent status was checked and patients who objected to the use of their data in health research were excluded from the analysis.

\section{Results}

A consecutive sample of 1'462 records were eligible and 1'276 LTC residents with at least 65 years of age were included in the analyses. Reasons for the exclusion of 186 cases $(12.7 \%)$ are shown in the study flow chart (Fig. 1: patients records).

\section{Inappropriate ED visits}

Figure 2 shows the patient characteristics as assessed for inappropriateness: overall, $6.0 \%(n=77)$ of the analysed patients were assessed as having inappropriate visits. Thus, the majority of referrals was deemed appropriate $\left(n=11^{\prime} 199 ; 94.0 \%\right)$. The agreement to assess inappropriate ED visit was very good (Gwet's AC $=0.92)$. The largest part of the sample had to be hospitalized $(n=878 ; 68.8 \%)$ and the remaining 398 patients had either a history of trauma with suspected fracture $(n=111 ; 8.7 \%)$, needed a radiological examination $(n=76 ; 6.0 \%)$, were referred for any other procedure, which could not be performed at the LTC facility $(n=78 ; 6.1 \%)$, or one of the other assessed parameters (Fig. 2: inappropriate ED-visits).

\section{Associations with inappropriate ED visits}

Characteristics of the analysed sample and associations with inappropriate ED visits are shown in Table 1. Median age was 84 years in both, appropriately (IQR 79-89) and inappropriately (IQR 77-88) admitted LTC residents and the admitted patients were predominantly female (62.0\%, resp. $64.9 \%)$. In the group of appropriate admissions, patients were more often admitted per ambulance $(68.3 \%$ vs. $46.8 \%, p<0.001)$ and were less often walk-in admissions $(20.8 \%$ vs $8.0 \%, p<0.001)$. Inappropriately referred patients were triaged into less urgent categories than appropriately referred patients $(p<0.001)$ (Table 1). 
Table 1

Distribution of potential predictor variables according to appropriateness

\begin{tabular}{|c|c|c|c|c|}
\hline & Total & Inappropriate & Appropriate & p- \\
\hline & $(n=1276)$ & $(n=77)$ & $(n=119)$ & value \\
\hline Age, [Med (IQR)] & $84.0(78-89)$ & $84.0(77-88)$ & $84.0(79-89)$ & 0.284 \\
\hline Sex, [Female, n (\%)] & $793(62.1)$ & $50(64.9)$ & $743(62.0)$ & 0.603 \\
\hline Consultation characteristi & 6) ]* & & & \\
\hline Night-time admission ${ }^{1}$ & $355(27.8)$ & $16(20.8)$ & $339(28.3)$ & 0.115 \\
\hline Type of admission & & & & \\
\hline Ambulance & $855(67.0)$ & $36(46.8)$ & $819(68.3)$ & \\
\hline General practitioner & $191(15.0)$ & $19(24.7)$ & $172(14.3)$ & \\
\hline Walk-in & $112(8.8)$ & $16(20.8)$ & $96(8.0)$ & \\
\hline Other & $30(2.4)$ & $3(3.9)$ & $27(2.3)$ & \\
\hline Missing & $88(6.9)$ & $3(3.9)$ & $85(7.1)$ & $<0.001$ \\
\hline Triage, [Med (IQR)] & $2.0(2-3)$ & $3.0(2-3)$ & $2.0(2-3)$ & $<0.001$ \\
\hline Comorbidity, [n (\%)]* & & & & \\
\hline $\mathrm{CCl},[\mathrm{Med}(\mathrm{IQR})]$ & $6.0(5-8)$ & $6.0(4-8)$ & $6.0(5-8)$ & 0.041 \\
\hline Congestive heart failure & $150(11.8)$ & $5(6.5)$ & $145(12.1)$ & 0.139 \\
\hline Myocardial infarction ${ }^{2}$ & $127(10.0)$ & $6(7.8)$ & $121(10.1)$ & 0.514 \\
\hline Chronic kidney disease & $455(35.7)$ & $22(28.6)$ & $433(36.1)$ & 0.180 \\
\hline Diabetes & $280(21.9)$ & $17(22.1)$ & $266(21.9)$ & 0.977 \\
\hline Liver disease & $81(6.3)$ & $4(5.2)$ & $77(6.4)$ & 0.669 \\
\hline COPD & $135(10.6)$ & $11(14.3)$ & $124(10.3)$ & 0.275 \\
\hline Dementia & $410(32.1)$ & $22(28.6)$ & $388(32.4)$ & 0.490 \\
\hline Cerebrovascular disease & $301(23.6)$ & $10(13.0)$ & $291(24.3)$ & 0.024 \\
\hline Hemi-/Paraplegia & $212(16.6)$ & $6(7.8)$ & $206(17.2)$ & 0.032 \\
\hline
\end{tabular}

*unless otherwise indicated

Capture: $\mathrm{CCl}=$ Charlson Comorbidity Index; $\mathrm{COPD}=$ Chronic obstructive lung disease; $\mathrm{ED}=$ Emergency Department; IQR = Interquartile Range; LOS = Length of stay; Med = Median; $\min =$ minutes; $P A C D=$ Peripheral artery occlusive disease; ${ }^{1}(6.00 \mathrm{pm}-6: 59 \mathrm{am}){ }^{2}$ History of myocardial infarction 


\begin{tabular}{|c|c|c|c|c|}
\hline & Total & Inappropriate & Appropriate & p- \\
\hline & $(n=1276)$ & $(n=77)$ & $(n=119)$ & value \\
\hline PACD & $98(7.7)$ & $10(13.0)$ & $88(7.3)$ & 0.071 \\
\hline Connective tissue disease & $7(0.5)$ & $3(3.9)$ & $4(0.3)$ & $<0.001$ \\
\hline Peptic ulcer & $41(3.2)$ & $3(3.9)$ & $38(3.2)$ & 0.726 \\
\hline Malignancy & $267(20.9)$ & $10(13.0)$ & $257(21.4)$ & 0.077 \\
\hline \multicolumn{5}{|l|}{ Outcome } \\
\hline LOS ED (h), [Med (IQR)] & $5.0(3.2-7.1)$ & $3.8(2.5-6)$ & $5.0(3.3-7.2)$ & 0.008 \\
\hline Hospitalization, [n (\%)] & $878(68.8)$ & $0(0.0)$ & $878(73.2)$ & $<0.001$ \\
\hline In-hospital death, [n (\%)] & $83(6.5)$ & $0(0.0)$ & $83(6.5)$ & 0.017 \\
\hline \multicolumn{5}{|l|}{ *unless otherwise indicated } \\
\hline \multicolumn{5}{|c|}{$\begin{array}{l}\text { Capture: } \mathrm{CCI}=\text { Charlson Comorbidity Index; } \mathrm{COPD}=\text { Chronic obstructive lung disease; } \mathrm{ED}=\text { Emergency } \\
\text { Department; IQR = Interquartile Range; } \mathrm{LOS}=\mathrm{Length} \text { of stay; } \text { Med = Median; } \min =\text { minutes; } \mathrm{PACD}= \\
\text { Peripheral artery occlusive disease; }{ }^{1}(6.00 \mathrm{pm}-6: 59 \mathrm{am}){ }^{2} \text { History of myocardial infarction }\end{array}$} \\
\hline
\end{tabular}

The total sample as well as both analysed groups had a high median CCI-Score of 6 points (IQR total sample and subjects rated "appropriate": $5-8$ ). For the group rated as inappropriate the score was, however, significantly lower (IQR 4-8); $p=0.041$ ). Regarding specific co-morbidities, less cerebrovascular diseases $(p=0.024)$ and Hemi-/paraplegia $(p=0.032)$ and more connective tissue diseases (such as systemic lupus erythematosus or scleroderma; $p<0.001$ ) were present in the group of inappropriately admitted patients.

\section{ED resource needs and ED of inappropriate visits}

Total resources needed by the LTC residents in the ED differed significantly between groups with almost two times the amount of total ED costs spent for appropriate admissions compared to inappropriate visits (Median 1567 vs. 805 Swiss Francs ( 1 Swiss Franc $\approx 1.003$ \$; $p<0.001$ ) caused by an increased nurse, laboratory, and by definition radiology resource need (Table 2). Physician work did not differ significantly between the groups $(p=0.466)$. 
Table 2

Distribution of potential predictor variables according to appropriateness.

\begin{tabular}{|c|c|c|c|c|}
\hline & $\begin{array}{l}\text { Total } \\
(n=1276)\end{array}$ & $\begin{array}{l}\text { Inappropriate }(\mathrm{n}= \\
\text { 77) }\end{array}$ & $\begin{array}{l}\text { Appropriate }(n= \\
1199)\end{array}$ & $\begin{array}{l}\mathrm{P} \text { - } \\
\text { value }\end{array}$ \\
\hline Total resources [TP] & $\begin{array}{l}1327(716- \\
1849)\end{array}$ & $568(226-828)$ & 1403 (795-1889) & $\begin{array}{l}< \\
0.001\end{array}$ \\
\hline \multicolumn{5}{|l|}{ Resource subgroups } \\
\hline Physician work [TP] & $447(258-651)$ & $435(362-663)$ & $450(247-650)$ & 0.466 \\
\hline $\begin{array}{l}\text { Physician patient time } \\
\text { [min] }\end{array}$ & $60(30-80)$ & $60(46-85)$ & $60(30-80)$ & 0.415 \\
\hline $\begin{array}{l}\text { Physician admin time } \\
\text { [min] }\end{array}$ & $50(25-75)$ & $55(35-80)$ & $50(25-75)$ & 0.178 \\
\hline $\begin{array}{l}\text { Physician report time } \\
\text { [min] }\end{array}$ & $20(11-20)$ & $20(11-20)$ & $20(11-20)$ & 0.227 \\
\hline Nurse work [TP] & $87(35-93)$ & $35(0-58)$ & $93(35-93)$ & $\begin{array}{l}< \\
0.001\end{array}$ \\
\hline Laboratory [TP] & $251(92-390)$ & $81(0-181)$ & $267(117-408)$ & $\begin{array}{l}< \\
0.001\end{array}$ \\
\hline Radiology [TP] & $318(58-838)$ & $0(0-64)$ & $345(58-887)$ & $\begin{array}{l}< \\
0.001\end{array}$ \\
\hline \multicolumn{5}{|c|}{ Administrative outcome, [Swiss Francs*] } \\
\hline $\begin{array}{l}\text { Total ED costs per } \\
\text { patient }\end{array}$ & $\begin{array}{l}1515(785- \\
2118)\end{array}$ & $805(472-1133)$ & 1454 (837-2161) & $\begin{array}{l}< \\
0.001\end{array}$ \\
\hline \multicolumn{5}{|c|}{ * 1 Swiss Franc $\approx 1.003$ USD; The values are presented as median (interquartile range) } \\
\hline
\end{tabular}

\section{Predictors of inappropriate ED visits}

The multivariable model to predict inappropriate ED visits is shown in Table 3

The odds for an inappropriate visit were higher for a less acute triage class and connective tissue disease (both $p \leq 0.001)$ and lower for night-time admissions $(p=0.035)$, and cerebrovascular diseases $(p=$ $0.043)$, respectively. Additionally, a significant likelihood to consume less resources $(p<0.001)$ was shown.

Goodness of fit analysis revealed $p=0.998$ (Hosmer-Lemeshow) and area under ROC curve $=0.784$. 
Table 3

Stepwise backward logistic regression to model inappropriate ED visits.

Inappropriate ED visits $\left(n=1261^{*}\right)$

Odds Ratio $(95 \% \mathrm{Cl})$

p-value

\section{Consultation characteristics}

Triage, less acute

Night admission

Total ED resources (In-transformed), per point more

\section{Comorbidities}

Congestive heart failure

Cerebrovascular Disease

Malignancy

COPD

PAOD

Connective tissue disease

* in 15 consultations the triage category was missing.

Capture: $E D=$ emergency department; $P A O D=$ peripheral artery occlusive disease; $C O P D=$ chronic obstructive pulmonary disease; $\mathrm{Ml}=$ myocardial infarction

\section{Discussion}

This single-center data-analysis assessed incidence, potentially associated risk factors, and usage of resources of inappropriate hospital referrals of LTC residents to a Swiss tertiary hospital ED. The results add to the discussion about new strategies regarding resource management and best possible care. Within the analyzed sample, $6.0 \%$ of LTC-facility referrals were assessed as inappropriate. This is relatively low, when compared to $4-55 \%$ found in a recent systematic review (14), including studies from Europe, the US, Australia, and Asia $(12,13,24)$. Still, admission rates and, alongside, inappropriate EDvisits are rising in Switzerland as well (25). As this comes along with increased morbidity of LTC residents (10) and is most probably also contributing to high healthcare costs (26), we agree with others authors that this topic should get more attention from health policy makers (27).

Mostly patients with low acuteness according to the Swiss triage scale or without the need for an invasive intervention were judged "inappropriate". The odds of an inappropriate visit for patients with a non-urgent triage was higher when compared to high urgent triage patients.

ED visits of patients with connective tissue diseases (such as systemic lupus erythematosus and scleroderma) were more likely to be assessed inappropriate. Although the total number of patients with 
rheumatic comorbidities - a condition that might be prone to subacute problem - was very low $(n=7)$, it can be assumed that diseases of complex organs generally more often require hospitalizations or invasive interventions than connective tissue diseases, and are, therefore, more often necessary. These findings reflect the results from previous investigations, where common reasons for inappropriate visits are described as non-emergent symptoms or condition manageable by a general practitioner $(24,28)$. On the other hand, the fact that the visit was appropriate does not mean, it was not avoidable: the early detection and treatment of deteriorating symptoms, especially with diagnoses like congestive heart failure, helps prevent exacerbations and avoid ED visits for acute situations no longer controllable in the nursing home.

In our sample, procedures not possible to perform in nursing homes (e.g. radiological examinations, indwelling urethral catheters and other procedures), accounted for more than $10 \%$ of all transferred LTC residents. Although these cases were not rated as inappropriate visits, some of these procedures might been manageable in an ambulatory care setting as well. Thus, appropriate visits may be overestimated and improvement of surveillance and adequate risk assessment in acute care situations or changes in conditions of LTC residents may be a factor to focus on, when trying to reduce inadequate ED-referrals of LTC-residents. This could be addressed with better access to primary care providers, be it general practitioners (23) or nurse practitioners, or a structured medical system within the nursing home which provides quicker access to expertise on site. A corresponding initiative with the introduction of nurse practitioners in nursing homes has achieved a reduction in all-cause hospitalizations up to $30 \%(11)$. That way, health care expenses may be reduced, as costly ED resources may be avoided. While fortunately the total ED resource consumption by inappropriately admitted patients was, in our sample, significantly lower compared to appropriate admissions, still a total of 49'295 tax points was needed for LTC-facility residents, which may have been more cost-effectively treated elsewhere. Although, consumed nurse work resources as well as laboratory, and - by definition - radiology ED resource consumption of inappropriately admitted patients was smaller compared to the appropriately admitted patients, physicians' work resources did not differ between the study groups. This indicates, that inappropriate ED visits are still resource-intensive consultations.

When reviewing the reports of the inappropriately referred patients, it was found that patients were often transferred for check-ups or examinations, while an acute event was missing in the patients' history. Other patients were admitted in a critical condition, but they were transferred back to the nursing homes, because the patient wanted to abstain from an invasive intervention. This indicates that some of the admissions might have been avoided by Advanced Care Planning (ACP), i.e. the assessment of and continuous conversation about residents' and their families wishes for treatment in acute situations, which has been shown to be effective in reducing hospital admissions (29).

Regardless of the status of appropriateness, high multimorbidity with a median score of 6 in the CCl was found for the sample. These findings correspond with other data from Switzerland, where LTC residents have a higher level of multimorbidity than their community-dwelling peers (4). About $85.5 \%$ have at least two different diagnoses, $22.8 \%$ of them even have five or more different chronic diagnoses (4).

Page 10/18 
As this further contributes to polypharmacy as well as high admission and hospitalization rates $(2,3,30)$, this finding corroborates the importance of interventions like ACP, palliative care, care pathways and geriatric specialist services or the introduction of advanced practice nurses to be considered for the population at risk $(11,31)$.

Further, hospital admission rates have also been attributed to a variety of non-medical factors including for-profit ownership of the LTC, poor environmental quality or lack of administrative emphasis on staff satisfaction, whereas higher total direct-care nursing hours per resident day, and presence of allied health staff - disproportionately present in publicly owned facilities - were associated with lower transfer rates $(32,33)$. Taken together, for Switzerland, several barriers need to be addressed: LTC residents often keep their GP during their stay and due to GP's lack of service hours during nights and weekends or difficulty to offer onsite visits adequate medical assessment is impeded $(27,34)$. Here, off-hours telemedicine coverage could play a role in the future (35). Importance should also be given to the availability of diagnostic equipment and adequate training for nurses and, further, time for direct-care nursing should be ensured $(29,32,34,35)$.

\section{Limitations}

The present investigation is limited by several factors. Firstly, there is little consensus in classifying inappropriate hospitalizations (36) and there are several methods to assess whether an admission is appropriate, and none of them is validated so far. The results may differ according to the instruments used and the use of a single tool may bias the current analysis (14). However, the tool by Finn et al. deemed to be the most suitable to use, because it was specifically designed for ED visits as opposed to hospitalisations, and was used more frequently than others. Still, this instrument has at least one critical step within the decision-procedure: the question whether an observation or procedure is not possible to be performed in an LTC residential facility remains an assumption of the assessor. Although we predefined scenarios for those two items (Additional file 1: decision-tree inappropriate ED-visits), their validity remains unsure, as we could not obtain data about the different resources available at the specific LTC facilities, e.g. access to primary care and possibilities for risk assessments. Thus, the appropriateness status may be confounded for this item. We reduced this risk by using two independent, trained raters. Moreover, neither the specific referring LTC facility nor the specific reasons for the admission was investigated in detail. That way, no further information about the challenges and needs of the LTC-staff or resources accessible to them could be generated. Therefore, no definitive suggestions for improving the link between the LTC facilities and the medical care centres in the catchment area of the ED can be given. Also the lack of data on the topic of palliative care adds to the list of limitations. As data on end-of-life planning of the respective subjects in our sample was not obtained systematically, we could only assume from exemplary reports that ACP may have been insufficiently performed in the LTC-facility.

Last but not the least, this is a retrospective chart review and therefore prone to documentation error.

\section{Conclusion}


Inappropriate ED visits from LTC residential facilities to the emergency care service of the study centre were relatively rare but may be underestimated. Lack of urgency and re-transfers of patients with palliative care conditions were the common reasons for inadequate referrals. Preventive strategies focusing on high-quality ambulatory care might further reduce inappropriate emergency admissions. Future research investigating specific reasons for admissions to the emergency department is needed in order to come up with targeted actions for the reduction of patients' risk and unnecessary expenditures.

\section{Declarations}

\section{Conflict of interest}

MM has received a research grant from the Gottfried and Julia Bangerter-Rhyner-Foundation and the inhouse Clinical Trial unit. All other authors have no financial or personals conflicts to disclose.

\section{Authors' contributions}

K. Gaertner, MD, is responsible for the write-up of the manuscript and contributed to data-interpretation; S.K. Schuh, MD and B. Löw assessed the appropriateness status and are responsible for data-coding; M. Simon, Prof., M. Müller, MD, PD, and Franziska Zúñiga, PhD supervised S.K. Schuh and B. Löw and contributed to the data-interpretation and performed the conceptualization of the study; Additionally, M. Müller, MD, PD is responsible for data-analysis.

\section{Ethical considerations}

The study was performed according to Swiss law. The Bern ethics committee registered the study as a quality evaluation study (KEK 2019-00512) and waived the need for informed consent. General informed consent status was checked and patients who objected to the use of their data in health research were excluded from the analysis.

\section{Consent for publication}

We assure that we retrieved consent for publication from all contributing authors.

\section{Availability of Data and Materials}

Anonymized material can be obtained from the author.

\section{Funding and sponsors role}


This study was partially funded by a grant from the in-house Clinical Trials Unit (MM). The funding organization had no role in the design and conduct of the study; collection, management, analysis, and interpretation of the data; preparation, review, or approval of the manuscript; and decision to submit the manuscript for publication.

\section{Competing interests}

We assure that there exist no competing interests.

\section{References}

1. Maher RLHJ, Hajjar ER. Clinical consequences of polypharmacy in elderly. Expert Opinion on Drug Safety. 2014;13:57-65.

2. EIDesoky E. Pharmacokinetic-pharmacodynamic crisis in the elderly. Am J Ther. 2007;14:488-98.

3. Budnitz DSLM, Shehab N, Richards CL. Emergency Hospitalizations for Adverse Drug Events in Older Americans. N Engl J Med. 2011;365:2002-12.

4. Schweizerisches Gesundheitsobservatorium. Gesundheit in Der Schweiz - Fokus Chronische Erkrankungen. Neuchatel, 2015.

5. Spector WMR, Owens P, Limcangco R. Transitions between Nursing Homes and Hospitals in the Elderly Population, 2009.: Statistical Brief \#141. Healthcare Cost and Utilization Project (HCUP) Statistical Briefs.. Rockville (MD): Agency for Healthcare Research and Quality (US); 2006. Available from: http://www.ncbi.nlm.nih.gov/books/NBK109959/.

6. Gruneir A, Bell C, Bronskill S, Schull M, Anderson G, Rochon P. Frequency and pattern of emergency department visits by long-term care residents-a population-based study. J Am Geriatr Soc. 2010;58(3):510-7.

7. Kirsebom M, Hedstrom M, Wadensten B, Poder U. The frequency of and reasons for acute hospital transfers of older nursing home residents. Arch Gerontol Geriatr. 2014;58(1):115-20.

8. Graverholt BRT, Jamtvedt G, Ranhoff AH, Krüger K, Nortvedt MW. Acute hospital admissions among nursing home residents: a population-based observational study. BMC Health Services Research. 2011;11:126.

9. Briggs R, Coughlan T, Collins R, Neill D, Kennelly S. Review Nursing home residents attending the emergency department: clinical characteristics and outcomes. Q J MEd. 2013;106:803-8.

10. Dwyer R, Gabbe B, Stoelwinder J, Lowthian J. A systematic review of outcomes following emergency transfer to hospital for residents of aged care facilities. Age Ageing. 2014;43(6):759-66.

11. Rantz MJPL, Vogelsmeier A, Galambos C, Alexander G, Flesner M. Successfully Reducing Hospitalizations of Nursing Home Residents: Results of the Missouri Quality Initiative. J Am Med Dir Assoc. 2017;18:960-6. 
12. Binot I, Tavassoli N, Berard E. Nursing home residents in emergency department: risk factors of inapprorpiate or potentially aviodable transfers. Results of a fine pilot study. J Nurs Home Res Sci. 2017;3(1):28-37.

13. Finn J, Flicker L. E M. Interface between residential aged care facilities and a teaching hospital emergency department in Western Australia. Med J Aust. 2006;184(9):432-5.

14. Lemoyne SE, Herbots HH, De Blick D, Remmen R, Monsieurs KG, Van Bogaert P. Appropriateness of transferring nursing home residents to emergency departments: a systematic review. BMC Geriatr. 2019;19(1):17.

15. Fortinsky RHME, Sheehan TJ, Tullai-McGuinness S, Kleppinger A. Risk Factors for Hospitalization in a National Sample of Medicare Home Health Care Patients. J Appl Gerontol. 2014;33:474-93.

16. Saliba DKR, Buchanan J, Bell R, Wang M, Lee M. Appropriateness of the Decision to Transfer Nursing Facility Residents to the Hospital. J Am Geriatr Soc. 2000;48(154-163):10.1111/j.532-

5415.2000.tb03906.x.

17. Exadaktylos AK, Hautz WE. Emergency Medicine in Switzerland. ICU Manag Pract. 2015;15.

18. Gertman PM, Restuccia JD. The Appropriateness Evaluation Protocol. Med Care. 1981;19(8):855-71.

19. Rutschmann O, Sieber R, Hugli O. Recommandations de la SSMUS pour le triage dans les services d'urgences hospitaliers en Suisse. Bulletin des médecins suisse. 2009;90(46):1789-90.

20. Deyo R, Cherkin D, Ciol M. Adapting a clinical comorbidity index for use with ICD-9-CM administrative databases. J Clin Epidemiol. 1992;45:613-9.

21. Halfon P, Eggli Y, Melle GV, Chevalier J, Wasserfallen J, Burnand B. Measuring potentially avoidable hospital readmissions. J Clin Epidemiol. 2002;55(6):573-87.

22. Gwet KL. Computing inter-rater reliability and its variance in the presence of high agreement. $\mathrm{Br} \mathrm{J}$ Math Stat Psychol. 2008;61(Pt 1):29-48.

23. Wongpakaran N, Wongpakaran T, Wedding D, Gwet KL. A comparison of Cohen's Kappa and Gwet's AC1 when calculating inter-rater reliability coefficients: a study conducted with personality disorder samples. BMC Med Res Methodol. 2013;13:61.

24. Manckoundia P, Menu D, Turcu A. Analysis of Inappropriate Admissions of Residents of Medicalized Nursing Homes to Emergency Departments: A Prospective Multicenter Study in Burgundy. J Am Med Dir Assoc. 2016;17(7):671. .e1-e7.

25. Carron P-N, Mabire C, Yersin B, Büla C. Nursing home residents at the Emergency Department: a 6year retrospective analysis in a Swiss academic hospital. Intern Emerg Med. 2017;12(2):229-37.

26. Di Somma S, Paladino L, Vaughan L, Lalle I, Magrini L, Magnanti M. Overcrowding in emergency department: an international issue. Intern Emerg Med. 2015;10(2):171-5.

27. Merçay C. Le recours aux services d'urgence en Suisse. Description des différences cantonales. 2018.

28. Codde J, Frankel J, Arendts G, Babich P. Quantification of the proportion of transfers from residential aged care facilities to the emergency department that could be avoided through improved primary 
care services. Australas J Ageing. 2010;29(4):167-71.

29. Martin RS, Hayes B, Gregorevic K, Lim WK. The Effects of Advance Care Planning Interventions on Nursing Home Residents: A Systematic Review. J Am Med Dir Assoc. 2016;17(4):284-93.

30. Mangin D, Heath I. M J. Beyond diagnosis: rising to the multimorbidity challenge. BMJ. 2012(3526):9-11.

31. Graverholt BFL, Jamtvedt G. Reducing hospital admissions from nursing homes: a systematic review. BMC Health Services Research. 2014;14:36.

32. Zimmerman SGBA, Hebel JR, Sloane PD, Magaziner J. Nursing Home Facility Risk Factors for Infection and Hospitalization: Importance of Registered Nurse Turnover, Administration, and Social Factors. J Am Geriatr Soc. 2002;50:1987-95.

33. McGregor MJ, Abu-Laban RB, Ronald LA, McGrail KM, Andrusiek D, Baumbusch J, et al. Nursing home characteristics associated with resident transfers to emergency departments. Can J Aging. 2014;33(1):38-48.

34. Giger M, Voneschen N, Brunkert T, Zuniga F. Care workers' view on factors leading to unplanned hospitalizations of nursing home residents: A cross-sectional multicenter study. Geriatr Nurs. 2019.

35. Ouslander JGNI, Engstrom G, Shutes J, Wolf DG, Alpert G. Root cause analyses of transfers of skilled nursing facility patients to acute hospitals: lessons learned for reducing unnecessary hospitalizations. J Am Med Dir Assoc. 2012;17:256-62.

36. Grabowski DCSK, Broderick SM, Coots LA. Predictors of nursing home hospitalization: a review of the literature. Med Care Res Rev. 2008;65:3-39.

37. Cassini A, Högberg LD, Plachouras D, Quattrocchi A, Hoxha A, Simonsen GS, et al. Attributable deaths and disability-adjusted life-years caused by infections with antibiotic-resistant bacteria in the EU and the European Economic Area in 2015: a population-level modelling analysis. Lancet Infect Dis. 2019;19(1):56-66.

\section{Figures}


Consultations identified through the administration software admitted from a long-term-care facility to the emergency department from 01.01.2015 -

31.12.2017 $(n=1700)$

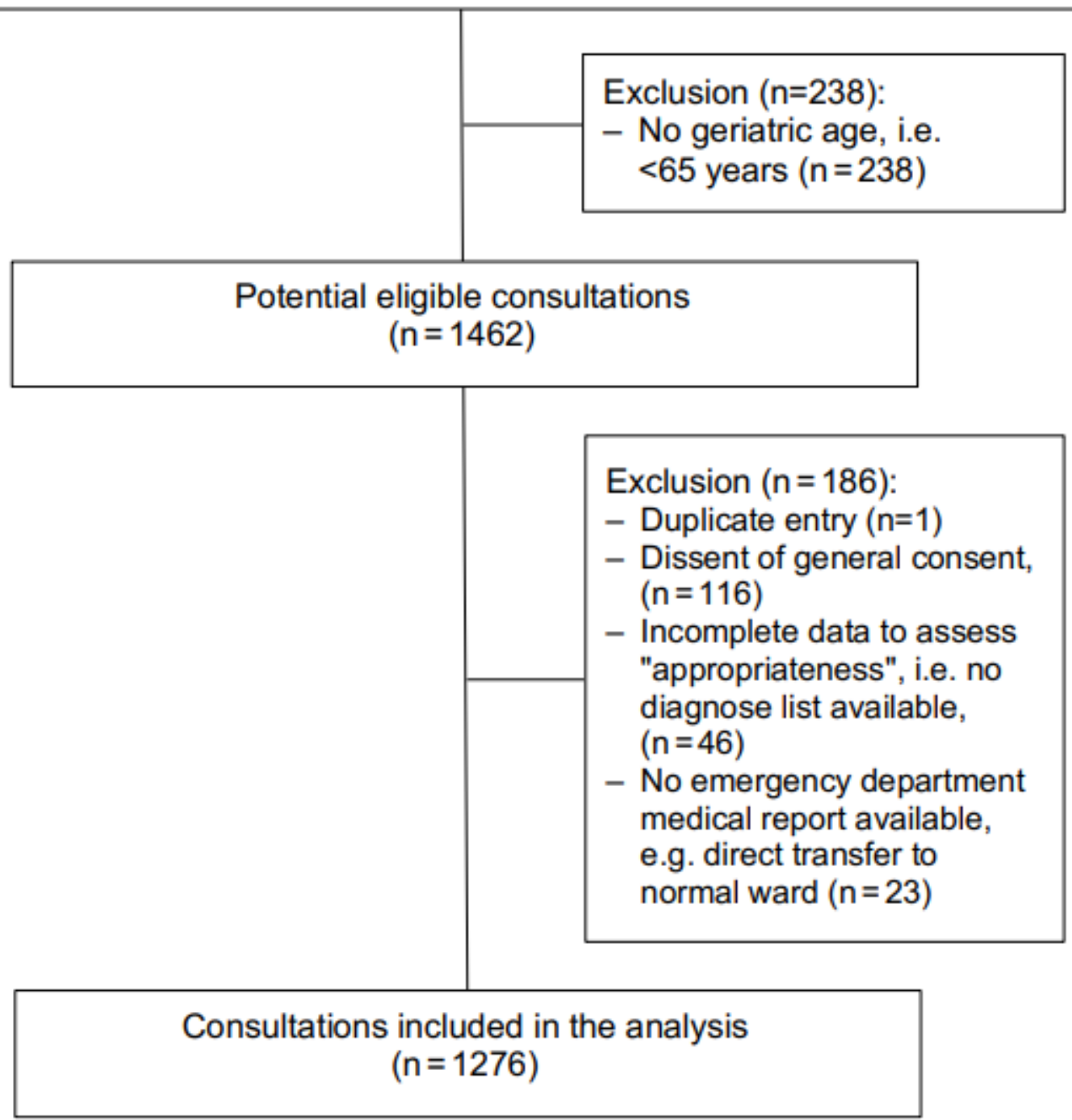

Figure 1

Flowchart of patients records 


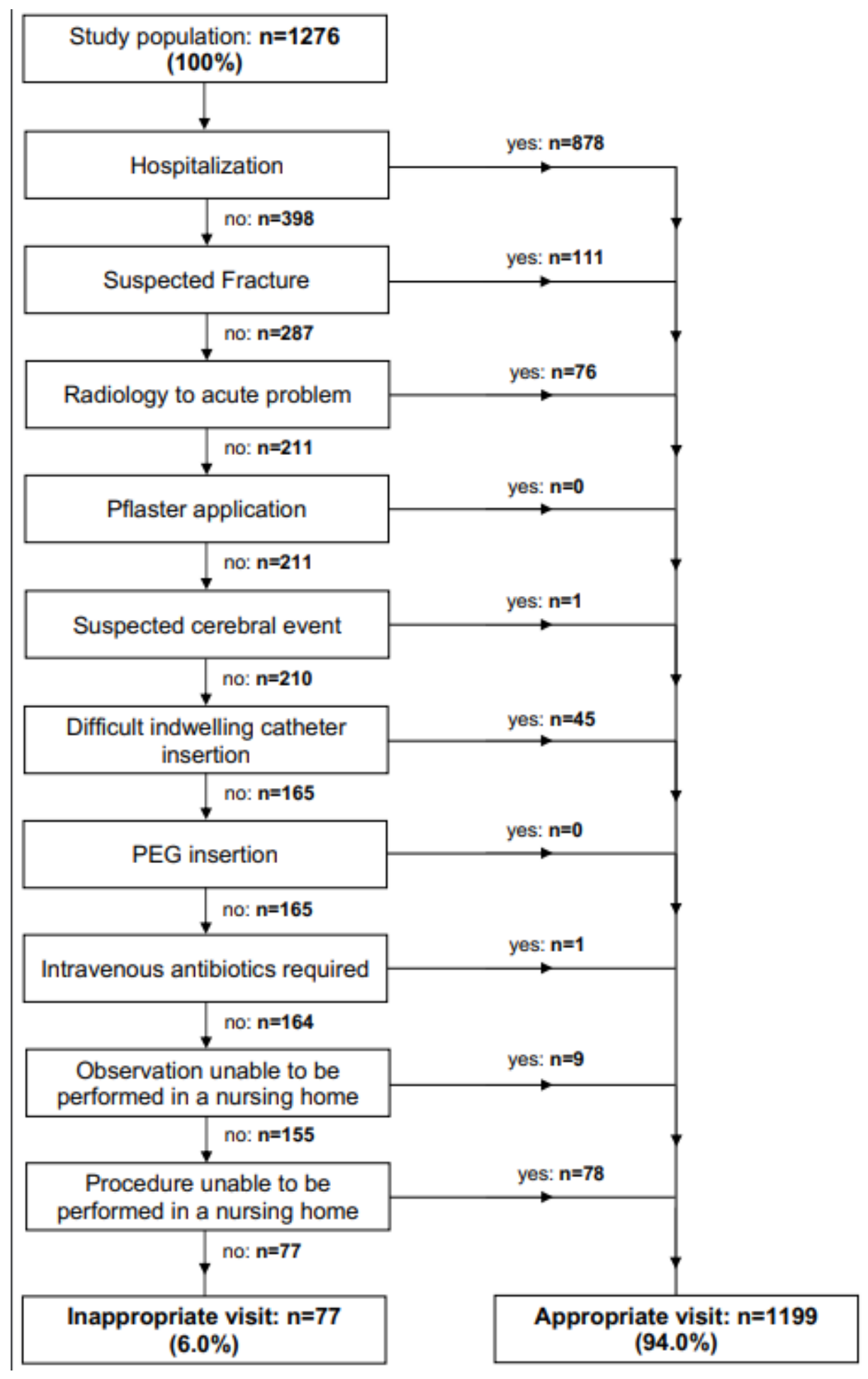

Figure 2

Inappropriate ED-visits

\section{Supplementary Files}

This is a list of supplementary files associated with this preprint. Click to download.

- Additionalfile.pdf 
- Additionalfile.pdf

Page 18/18 